\title{
Corrigendum
}

\section{An analysis of monthly home range size in the critically endangered California Condor Gymnogyps californianus - CORRIGENDUM}

\author{
JAMES W. RIVERS, J. MATTHEW JOHNSON, SUSAN M. HAIG, CARL J. SCHWARZ, \\ L. JOSEPH BURNETT, JOSEPH BRANDT, DANIEL GEORGE and JESSE GRANTHAM
}

doi:10.1017/S0959270913000592, Published by Cambridge University Press, 1o March 2014.

In the above paper (Rivers et al. 2014), all estimates of monthly home range in the manuscript should have been reported as geometric means.

The following figure legends should read:

Figure 2. Geometric mean ( $\pm 95 \% \mathrm{CI}$ ) monthly home range size of immature (filled circles) and adult California Condors (open circles) across the annual cycle.

Figure 3. Geometric mean $( \pm 95 \% \mathrm{CI})$ monthly home range size of adult female and male California Condors relative to breeding status.

Figure 4 . Geometric mean $( \pm 95 \% \mathrm{CI})$ monthly home range size of California Condors that were raised in the wild by their genetic parents or reared in captivity.

Figure 5 . Geometric mean $( \pm 95 \% \mathrm{CI})$ monthly home range size of California Condors from the three release sites in southern and central California (i.e., FWS $=$ Hopper Mountain National Wildlife Refuge Complex) and central California (i.e., PNM = Pinnacles National Monument, VWS = Ventana Wildlife Society).

\section{Reference}

Rivers, J.W., Johnson, J. M., Haig, S. M., Schwarz, C. J., Burnett, L. J., Brandt, J., George, D. and Grantham, J. (2014) An analysis of monthly home range size in the critically endangered California Condor Gymnogyps californianus. Bird Conserv. Int. 24: 492-504. 